\title{
Co-expression of CXCR4 and CD133 proteins is associated with poor prognosis in stage II-III colon cancer patients
}

\author{
NIAN-HUA ZHANG ${ }^{1,2^{*}}$, JIE LI $^{3 *}$, YIN LI $^{4}$, XIN-TAO ZHANG ${ }^{5}$, WEN-TING LIAO ${ }^{6-8}$, \\ JUN-YI ZHANG ${ }^{1}$, RONG LI ${ }^{1}$ and RONG-CHENG LUO ${ }^{1}$ \\ ${ }^{1}$ Department of Oncology, Nanfang Hospital, Southern Medical University, Guangzhou 510515; \\ ${ }^{2}$ Department of Oncology, Guangdong Second Provincial Traditional Chinese Medicine Hospital, Guangzhou 510095; \\ Departments of ${ }^{3}$ Vascular Surgery, and ${ }^{4}$ Gastrointestinal Surgery, The First Affiliated Hospital, Sun Yat-Sen University, \\ Guangzhou 510080; ${ }^{5}$ Department of Sports Medicine, Peking University Shenzhen Hospital, Shenzhen 518036; \\ ${ }^{6}$ Department of Pathology, School of Basic Medical Sciences, Southern Medical University, Guangzhou 510515; \\ ${ }^{7}$ Department of Pathology, Nanfang Hospital, Southern Medical University, Guangzhou 510515; \\ ${ }^{8}$ Guangdong Provincial Key Laboratory of Molecular Tumour Pathology, Guangzhou 510515, P.R. China
}

Received January 21, 2012; Accepted March 21, 2012

DOI: $10.3892 / \mathrm{etm} .2012 .527$

\begin{abstract}
Although CXCR4 and CD133 have been implicated in the metastatic process of malignant tumors, the clinicopathological significance of their expression in human colon cancer is not fully understood. The present study aimed to examine the expression of the CXCR4 and CD133 proteins in cases of stage II or III colon cancer and the related lymph nodes and to investigate the clinical and prognostic significance of these proteins in colon cancer. Immunohistochemical analysis was performed to examine CXCR4 and CD133 protein expression in paraffin-embedded stage II or III primary colon cancer tissues and matched lymph nodes. The correlation between the expression of the two proteins and clinicopathological parameters and the patient 5-year survival was analyzed. CXCR4 expression was detected in 74 of the 125 tumors (59.2\%) and CD133 expression was detected in 45 (36.0\%). The co-expression of CXCR4 and CD133 (both CXCR4 and CD133 were positive) was detected in 29 of the 125 tumors (23.2\%). Compared with the other combinations, the co-expression of the CXCR4 and CD133 proteins was significantly associated with American Joint Committee on Cancer (AJCC) stage $(\mathrm{P}=0.029)$ and lymph node status $(\mathrm{P}=0.020)$. Log-rank analysis revealed that AJCC stage $(\mathrm{P}=0.014)$, lymph node status $(\mathrm{P}=0.011), \mathrm{CXCR} 4$ expression $(\mathrm{P}=0.023), \mathrm{CD} 133$ expression $(\mathrm{P}=0.034)$ and the co-expression of the CXCR4 and CD133
\end{abstract}

Correspondence to: Professor Rong-Cheng Luo, Department of Oncology, Nanfang Hospital, Southern Medical University, Guangzhou 510515, P.R. China

E-mail: luorc01@163.com

*Contributed equally

Key words: CXCR4, CD133, colon cancer, immunohistochemistry proteins $(\mathrm{P}=0.003)$ were significant prognostic indicators for the overall survival of patients. The results of the present study show that the co-expression of the CXCR4 and CD133 proteins is a risk factor for poor overall survival in stage II or III colon cancer patients, indicating that the co-expression of the CXCR4 and CD133 proteins contributes to the progression of colon cancer.

\section{Introduction}

Colon cancer is one of the three leading causes of cancer-related mortality worldwide and survival is affected by local recurrence and lymphatic and hematogenous dissemination (1). This neoplasm frequently metastasizes to the lymph nodes at early stages of the disease. In advanced disease, the majority of patients develop extra lymph node metastases, most often in the liver, lungs and peritoneum. An understanding of the factors involved in colon cancer metastasis is largely lacking. At present, the growth and metastasis of tumors are considered to be due to the dysregulation of molecular processes. This also gives rise to several features of tumor cells, including resistance to apoptosis, migration, invasion and the ability to escape the immune system. The results of previous studies indicate that chemokine receptors direct the lymphatic and hematogenous spread of tumors and may also influence the site of metastasis (2-5).

CXCR4 is a chemokine receptor that was first identified as a regulator of the homing of lymphocytes in inflammatory tissues (6). Stromal cell-derived factor (SDF)- $1 \alpha$ is a ligand of CXCR4 and has high levels of expression in sites of metastasis, including the lung, liver and lymph nodes, where it attracts lymphocytes (7). It has been shown that CXCR4 is critical for the adhesion and/or migration of tumor cells, indicating that CXCR4 is involved in tumor invasion and metastasis (8). Numerous authors have reported on the involvement of the CXCR4/SDF-1 $\alpha$ axis in promoting a metastatic phenotype in tumors (9-18). For example, high CXCR4 expression has been 
shown to be associated with lymph node metastasis in breast cancer and oral squamous cell carcinoma $(19,20)$.

An increasing amount of experimental evidence supports the hypothesis that stem cells play a significant role in the progression of cancer. Cancer stem cells are able to self-renew and are believed to drive tumor growth $(21,22)$. Thus far, cancer stem cells have been identified in a great number of solid tumors $(23,24)$. CD133 is a well-studied cancer stem cell marker that has been implicated in numerous types of solid tumors, including colorectal cancer (25-27). Preliminary evidence suggests that CD133 is involved in bioenergetic stress, resistance to apoptosis and the activation of a stemness-related signaling pathway, although its function is unknown (28-33). CD133 was first described in hematopoietic stem cells and is now established as a cancer stem cell marker in a number of types of solid tumors, including those of the brain, breast, lung, liver, colon and prostate as well as in pancreatic carcinomas, medulloblastoma and melanoma (34-38). The cancer stem cell compartment is increasingly being recognized as a necessary target for the effective treatment of cancers (39) and supporting data from in vitro and murine tumor models have underlined the key roles of CXCR4 and CD133 in tumor cell malignancy. However, no data are presently available concerning the co-expression of the two proteins in human colon cancer and the impact of these proteins on disease progression and prognosis. Therefore, we evaluated the expression of CXCR4 and CD133 in colon cancer specimens and correlated the results with the clinicopathological parameters and survival of the patients.

\section{Materials and methods}

Patients and follow-up. A total of 125 pathologically confirmed specimens were obtained from colon cancer patients with TNM stage II or III tumors that were subjected to radical resection between January 2001 and July 2005 in The First Affiliated Hospital, Sun Yat-Sen University (Guangzhou, China). None of the patients had undergone either chemotherapy or radiotherapy prior to the collection of the samples. Postoperative therapeutic strategies were applied according to the stage of the disease and the presumed risk of relapse. Patients with stage II disease underwent follow-up based on history, physical examination, complete blood count, liver function tests, ultrasound scan of the abdomen and carcinoembryonic antigen monitoring every three months. Total body computed tomography scan and colonoscopy were performed once a year. Patients with stage II high-risk disease ( $\mathrm{pT}_{4}$ and/or gross volume tumors, perforation, obstruction, poorly differentiated histology, long-lasting symptoms, preoperative elevated carcinoembryonic antigen levels or blood or lymphatic vessel invasion) were encouraged to undergo adjuvant chemotherapy. If no contraindications were present, patients with stage III disease underwent six months of fluorouracil (Fu)-based adjuvant chemotherapy and were then followed up. A total of 90 patients received Fu-based adjuvant chemotherapy and 35 stage II patients did not receive adjuvant interventions. The patients were observed once every three months during the first year, once every six months in the second year and by telephone or mail communication once every year thereafter for a total of 5 years. If recurrence or metastasis occurred, 5-Fu-based chemotherapy was administered according to the National Comprehensive Cancer Network (NCCN) guidelines. Overall survival was defined as the time from surgery to mortality or was censored at the last known date alive. Histopathological characteristics were confirmed by a blinded review of the original pathology slides. The TNM classification was used for pathological staging and the World Health Organization classification was used for pathological grading.

Immunohistochemical assay. The expression of CXCR4 and CD133 in primary tumors and lymph node metastasis was examined using an immunohistochemical assay. The immunohistochemical assay was performed within seven days of section preparation. To prevent antigen degradation, the sections were stored at $4^{\circ} \mathrm{C}$ prior to the assay. Briefly, formalin-fixed, paraffin-embedded archived tissues were sectioned at a thickness of $4 \mu \mathrm{m}$. The sections were then dewaxed, rehydrated and blocked with hydrogen peroxide. The slides were then immersed in $10 \mathrm{mmol} / \mathrm{l}$ sodium citrate buffer ( $\mathrm{pH}$ 6.0) for CXCR4 staining or in $10 \mathrm{mmol} / \mathrm{l}$ citrate buffer ( $\mathrm{pH}$ 6.0) for CD133 staining, incubated for $10 \mathrm{~min}$ on a hot plate $\left(95-99^{\circ} \mathrm{C}\right)$ or boiled and allowed to cool for 20 min. For CXCR4 staining, following blocking with $1 \%$ goat serum albumin, the sections were incubated with mouse monoclonal antibodies against human CXCR4 at a dilution of 1:150 (Abcam, Cambridge, UK) for $2 \mathrm{~h}$ at room temperature, followed by a biotinylated secondary antibody and streptavidin-biotinylated horseradish peroxidase complex. For CD133 staining, following blocking with $1 \%$ goat serum albumin, the sections were incubated with mouse monoclonal antibodies against human CD133 at a dilution of 1:150 (Novus, Littleton, CO, USA) overnight at $4^{\circ} \mathrm{C}$, followed by the biotinylated secondary antibody and streptavidin-biotinylated horseradish peroxidase complex. The slides were stained for $5 \mathrm{~min}$ with $0.05 \%$ diaminobenzidine tetrahydrochloride (DAB) freshly prepared in $0.05 \mathrm{~mol} / \mathrm{l}$ Tris- $\mathrm{HCl}$ buffer ( $\mathrm{pH} 7.6$ ) containing $0.024 \%$ hydrogen peroxidase and then counterstained with hematoxylin, dehydrated and mounted. All series included positive controls (melanoma and glioma samples). Negative controls were obtained by substituting the primary antibody with a mouse myeloma protein of the same subclass at the same concentration as the monoclonal antibody. All controls yielded satisfactory results.

The specimens were evaluated by two authors (Y.L. and W.-T.L.) who had no knowledge of the prognosis or other clinicopathological variables. Following Matsumoto's method, each image was analyzed for immunoreactivity using a 0 to 3 semi-quantitation system for the intensity of staining and the percentage of positive cells (labeling frequency percentage) (40). The samples were grouped into the following four categories based on the intensity of membrane staining: 0 , no staining/background equal to the negative controls; 1 , weak staining detectable above background; 2 , moderate staining; 3, intense staining. The labeling frequency was scored as $0(0 \%), 1(1-33 \%), 2(34-66 \%)$ or $3(67-100 \%)$. The index sum was obtained by totaling the scores of intensity and percentages. If the final score was equal to or greater than four, the result was considered positive; otherwise, the result was considered negative. 
Statistical analysis. The associations between immunohistochemical scores and clinicopathological variables of the tissue specimens were evaluated using the $\chi^{2}$ test. When the subset sample size was small, the corresponding test was performed using Fisher's exact test. Univariate analysis was performed using the log-rank test. The Cox proportional hazards regression was used to analyze the effect of several risk factors on overall survival. The following factors were assessed using univariate and multivariate analyses for their influence on overall survival: gender, age ( $<60$ vs. $\geq 60$ years), location of the primary mass (left vs. right hemicolon), pathological grades [well-differentiated (G1), moderately differentiated (G2) or poorly differentiated (G3)], tumor size $(<2,2-5$ or $>5 \mathrm{~cm}$ ), American Joint Committee on Cancer (AJCC) stage (stage II vs. III), tumor invasion (pT1-T2, pT3 or pT4), lymph node status ( $\mathrm{pN} 0, \mathrm{pN} 1$ or $\mathrm{pN} 2$ ), CXCR4 expression (positive vs. negative), CD133 expression (positive vs. negative) and the combined expression of CXCR4 and CD133 (both positive vs. other combinations). Kaplan-Meier curves were used to estimate the contributions of the clinicopathological characteristics to survival. All analyses were performed using the Statistical Package for Social Sciences (SPSS) software, version 13.0, for Windows (SPSS Inc., Chicago, IL, USA). $\mathrm{P}<0.05$ was considered to indicate a statistically significant result. All reported P-values are two-sided.

\section{Results}

Characteristics of patients and tumors. A total of 125 patients seen between January 2001 and July 2005 were studied. The characteristics of all patients are summarized in Table I. The median age was 61.8 years; 68 patients were $\geq 60$ years old . The genders were equally represented. A total of 71 tumors originated in the left hemicolon. The majority of the patients $(102 / 125,81.6 \%)$ had moderate-grade disease. Approximately $62 \%$ of the patients had tumors between 2 and $5 \mathrm{~cm}$ in size, 61 patients presented with stage II disease and 64 with stage III. The majority of the lesions presented with a pT3 or pT4 extent of invasion and 64 patients presented with pN+ disease (Table I).

Expression of CXCR4 in colon epithelium and colon cancer tissues. In the normal colon epithelium adjacent to the tumor, weak immunoreactivity for CXCR4 was detected in the cytoplasm and plasma membrane of non-neoplastic epithelial cells (Fig. 1A and B). Paratumorous normal colon epithelium was observed in 102 of the 125 specimens used for this study and, of those 102, expression of CXCR4 in the colon epithelium was found in only 11 cases.

Of the 125 colon cancer tissues, 74 (59.2\%) were positive for CXCR4 expression. Staining for CXCR4 revealed a predominantly cytoplasmic and, in a few specimens, an additional weak membranous location of CXCR4. Nuclear staining of CXCR4 was not observed. Fig. 1 shows examples of CXCR4 staining of colon cancer tissues (Fig. 1A and B). In addition, some tumor-infiltrating lymphocytes and fibroblastic cells exhibited positive cytoplasmic staining for CXCR4.

Among the 125 stage II or III colon cancer patients, no significant correlation existed between CXCR4 expression
Table I. Clinicopathological features of the patients with colon cancer $(n=125)$.

\begin{tabular}{lc}
\hline Parameters & No. of patients \\
& $(\%)$ \\
\hline Age (years) & \\
$<60$ & $57(45.6)$ \\
$\geq 60$ & $68(54.4)$ \\
Gender & \\
Male & $78(62.4)$ \\
Female & $47(37.6)$ \\
Location & \\
Left hemicolon & $71(56.8)$ \\
Right hemicolon & $54(43.2)$ \\
Pathological grade & $14(11.2)$ \\
G1 & $102(81.6)$ \\
G2 & $9(7.2)$ \\
G3 & \\
Tumor size (cm) & $14(11.2)$ \\
$<2$ & $77(61.6)$ \\
$2-5$ & $34(27.2)$ \\
$>5$ & $60(48.0)$ \\
AJCC stage & \\
II & \\
III & $61(48(30.8)$ \\
Tumor invasion & \\
pT1-T2 & \\
pT3 & $64(51.2)$ \\
pT4 & \\
pNo 20.8$)$ \\
\hline
\end{tabular}

${ }^{\mathrm{a}} \mathrm{As}$ the number of patients with tumors of pT1 and pT2 stages was small, patients from these stages were combined for the analysis. Grading was according to World Health Organization classification; AJCC, American Joint Committee on Cancer.

and gender, age, location of primary mass, pathological grade, tumor size, AJCC stage, tumor invasion or lymph node status (Table II).

Expression of CD133 in colon epithelium and colon cancer tissues. In the normal colon epithelium adjacent to the tumor, CD133 expression was absent in the majority of cases and was mild and focal in intensity in the remainder (Fig. 1D and E). Paratumorous normal colon epithelium was observed in 102 of the 125 specimens used for this study. Expression of CD133 in the colon epithelium was found in only 8 of the 102 specimens.

CD133 expression was detected in 45 of the 125 tumors (36.0\%). CD133 expression in colon cancer was polar and confined to the apical luminal surface of colon cancer cells 

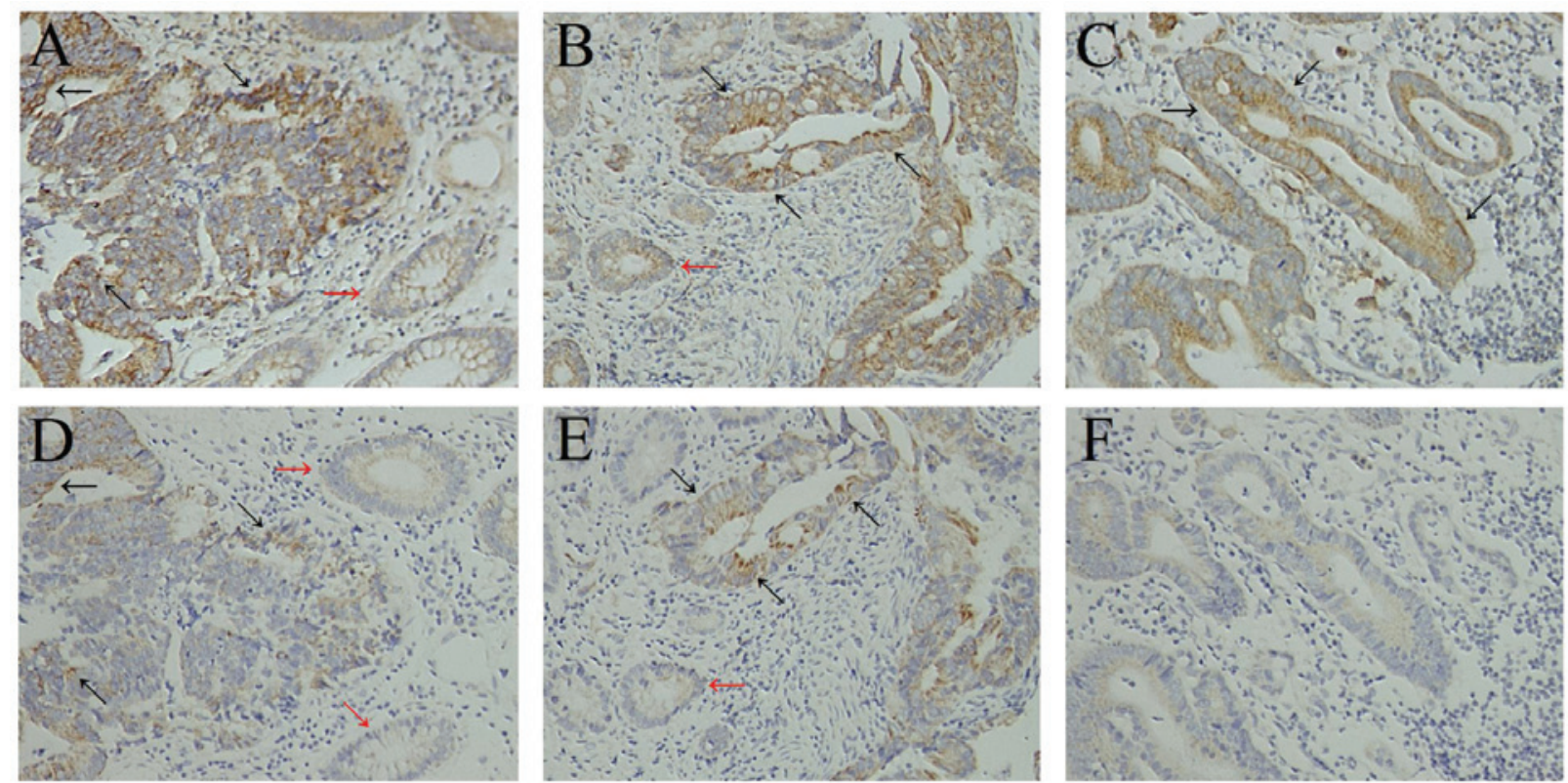

Figure 1. Immunohistochemical expression of CXCR4 and CD133 in colon cancer tissues. CXCR4 expression in (A) stage II colon cancer, (B) stage III colon cancer and (C) lymph node metastasis of stage III colon cancer. Compared with the primary lesions in stage III colon cancer (B), no difference in the expression of CXCR4 in metastasized tumors in lymph nodes (C) was observed. CD133 expression in (D) stage II colon cancer, (E) stage III colon cancer and (F) lymph node metastasis of stage III colon cancer. (E) Compared with the primary lesions in stage III colon cancer, (F) lymph node metastases were significantly more likely to show decreased CD133 expression. Black arrows indicate the positive cells, and red arrows indicate the normal colon epithelium adjacent to the tumor. Original magnification, x200. Staging according to American Joint Committee on Cancer.

with glandular differentiation, which is in accordance with previous results. We observed staining of CD133 on the luminal cell surface of colon cancer glands (Fig. 1D and E) and only tumor cells in direct contact with these luminal surfaces were $\mathrm{CD}_{133^{+}}$. CD133 ${ }^{+}$tumor cells were mostly observed in groups, with some glands being completely positive. In addition, tumor-infiltrating lymphocytes and fibroblastic cells did not exhibit positive cytoplasmic staining for CD133.

Among the 125 stage II or III colon cancer patients, no significant correlation existed between CD133 expression and gender, age, location of primary mass, pathological grade, tumor size, AJCC stage, tumor invasion or lymph node status (Table II).

Correlation between CXCR4 and CD133 expression in colon cancer. Among the 125 stage II or III colon cancer patients, no significant correlation was found between CXCR4 or CD133 expression and gender, age, location of primary mass, pathological grade, tumor size, AJCC stage, tumor invasion or lymph node status (Table II). CXCR4-positive colon cancer cases showed stronger CD133 expression than negative cases, but no significant difference was observed (Table III; $\mathrm{P}=0.371$ ). By combining the expression of CXCR4 and CD133, we obtained the following four combinations: CXCR4-positive and CD133-positive, CXCR4-positive and CD133-negative, CXCR4-negative and CD133-positive and CXCR4-negative and CD133-negative. Notably, co-expression (CXCR4- and CD133-positive) was detected in 29 of the 125 tumors (23.2\%) and, compared with the other combinations, the co-expression of the CXCR4 and CD133 proteins was significantly associated with the AJCC stage $(\mathrm{P}=0.029)$ and the lymph node status (Table II; $\mathrm{P}=0.020$ ).
Expression of CXCR4 and CD133 in metastasized tumors in lymph nodes (MTLNS). A total of 64 stage III colon cancer cases showed metastasis to their related lymph nodes. Among these primary cancer cases, $41(64.1 \%)$ showed a marked expression of CXCR4. Of the MTLNs, 43 (67.2\%) showed a marked expression of CXCR4. Thus, most of the stage III colon cancer cases $(n=41,64.1 \%)$ showed strong CXCR4 expression, not only in the primary lesions but also in their MTLNs (Fig. 1B and C; Table IV; $\mathrm{P}=0.710$ ).

Of the 64 stage III colon cancer cases, 27 (42.2\%) were positive for CD133 expression, but only 15 (23.4\%) of the MTLNs were positive for CD133 expression. These findings suggest that, compared with their primary lesions, MTLNs are significantly more likely to show decreased CD133 expression (Fig. 1E and F; Table IV; $\mathrm{P}=0.024$ ).

Upon combining the expression of CXCR4 and CD133, the co-expression of the CXCR4 and CD133 proteins was significantly different between the primary cancers and MTLNs. Notably, the primary cancers showed a marked co-expression of the CXCR4 and CD133 proteins (31.3\%), whereas in MTLNs, the co-expression was observed in only $14.1 \%$ of cases (Table IV; $\mathrm{P}=0.020$ ).

Survival analysis. All 125 patients were followed up for survival to assess CXCR4 and CD133 expression as a prognostic factor. The median follow-up period was 6.5 years. Of the 125 patients, 39 died during the follow-up period and the 5 -year survival rate was $68.8 \%$. The analysis of prognostic factors for survival is summarized in Table V. Log-rank analysis revealed that AJCC stage, lymph node status, CXCR4 expression, CD133 expression and the co-expression of the CXCR4 and CD133 proteins were significant prognostic 
Table II. Correlation between CXCR4 and CD133 expression and clinicopathological features in colon cancer patients.

\begin{tabular}{|c|c|c|c|c|c|c|c|c|c|}
\hline & \multicolumn{2}{|c|}{ CXCR4 } & \multirow[b]{2}{*}{ P-value } & \multicolumn{2}{|c|}{ CD133 } & \multirow[b]{2}{*}{ P-value } & \multicolumn{2}{|c|}{ CD133 and CXCR4 } & \multirow[b]{2}{*}{ P-value } \\
\hline & Positive & Negative & & Positive & Negative & & Both positive & Others & \\
\hline \multicolumn{10}{|l|}{ Age (years) } \\
\hline$<60$ & 34 & 23 & & 16 & 41 & & 9 & 48 & \\
\hline$\geq 60$ & 40 & 28 & 0.925 & 29 & 39 & 0.091 & 20 & 48 & 0.072 \\
\hline \multicolumn{10}{|l|}{ Gender } \\
\hline Male & 49 & 29 & & 31 & 47 & & 17 & 61 & \\
\hline Female & 25 & 22 & 0.289 & 14 & 33 & 0.261 & 12 & 35 & 0.632 \\
\hline \multicolumn{10}{|l|}{ Location } \\
\hline Left hemicolon & 43 & 28 & & 28 & 43 & & 19 & 52 & \\
\hline Right hemicolon & 31 & 23 & 0.722 & 17 & 37 & 0.359 & 10 & 44 & 0.28 \\
\hline \multicolumn{10}{|l|}{ Pathological grade } \\
\hline G1 & 5 & 9 & & 2 & 12 & & 0 & 14 & \\
\hline $\mathrm{G} 2$ & 63 & 39 & & 39 & 63 & & 27 & 75 & \\
\hline G3 & 6 & 3 & 0.159 & 4 & 5 & 0.186 & 2 & 7 & 0.089 \\
\hline \multicolumn{10}{|l|}{ Tumor size (cm) } \\
\hline$<2$ & 6 & 8 & & 2 & 12 & & 1 & 13 & \\
\hline $2-5$ & 50 & 27 & & 30 & 47 & & 18 & 59 & \\
\hline$>5$ & 18 & 16 & 0.207 & 13 & 21 & 0.199 & 10 & 24 & 0.251 \\
\hline \multicolumn{10}{|l|}{ AJCC stage } \\
\hline II & 33 & 28 & & 18 & 43 & & 9 & 52 & \\
\hline III & 41 & 23 & 0.257 & 27 & 37 & 0.140 & 20 & 44 & 0.029 \\
\hline \multicolumn{10}{|l|}{ Tumor invasion } \\
\hline $\mathrm{pT} 1-\mathrm{T} 2^{\mathrm{a}}$ & 7 & 9 & & 4 & 12 & & 2 & 14 & \\
\hline pT3 & 33 & 27 & & 26 & 34 & & 16 & 44 & \\
\hline pT4 & 34 & 15 & 0.127 & 15 & 34 & 0.240 & 11 & 38 & 0.485 \\
\hline \multicolumn{10}{|l|}{ Lymph node status } \\
\hline pNO & 33 & 28 & & 18 & 43 & & 9 & 52 & \\
\hline $\mathrm{pN} 1$ & 22 & 16 & & 15 & 23 & & 9 & 29 & \\
\hline $\mathrm{pN} 2$ & 19 & 7 & 0.252 & 12 & 14 & 0.290 & 11 & 15 & 0.020 \\
\hline
\end{tabular}

${ }^{\mathrm{a} A s}$ the number of patients with tumors of pT1 and pT2 stages was small, patients from these stages were combined for the analysis. Grading was according to World Health Organization classification; AJCC, American Joint Committee on Cancer.

Table III. Correlation between CXCR4 expression and CD133 expression in primary cancer.

\begin{tabular}{lccc}
\hline & \multicolumn{2}{l}{ CD133 expression $\mathrm{n}(\%)$} & \\
\cline { 2 - 3 } CXCR4 expression & Positive & Negative & P-value \\
\hline Positive & $29(39.2)$ & $45(60.8)$ & \\
Negative & $16(31.4)$ & $35(68.6)$ & 0.371 \\
\hline
\end{tabular}

indicators for overall patient survival (Table V). The predictive ability of the AJCC stage, lymph node status, CXCR4 expression, CD133 expression and co-expression of the CXCR4 and CD133 proteins was confirmed by multivariate analysis (Table V). No significant correlation was observed between the prognosis and the other clinicopathological features.
To assess the prognostic significance of CXCR4 and CD133 expression, Kaplan-Meier survival curves were constructed. The prognosis of colon cancer patients with positive CXCR4 expression was significantly worse than that of colon cancer patients with negative CXCR4 expression (Fig. 2A). Patients with CD133-positive colon cancers also had significantly poorer outcomes than those with CD133-negative tumors (Fig. 2B). Furthermore, colon cancer patients with co-expression of CXCR4 and CD133 proteins tended to have poorer outcomes than those with other combinations (Fig. 2C). The Kaplan-Meier estimated curves suggest that the prognosis is particularly unfavorable for patients whose primary tumors express both CXCR4 and CD133. Of the patients with co-expression of the CXCR4 and CD133 proteins, the 5-year survival rate was only $48.3 \%$; by contrast, the survival rate was $75.0 \%$ in patients with tumors that expressed the other combinations (log-rank test, $\mathrm{P}=0.003$ ). 
Table IV. Correlation between CXCR4 and CD133 expression in primary cancer and in lymph node metastasis of stage III colon cancer patients.

\begin{tabular}{|c|c|c|c|c|c|c|c|c|c|}
\hline & \multicolumn{2}{|c|}{ CXCR4 } & \multirow[b]{2}{*}{ P-value } & \multicolumn{2}{|c|}{ CD133 } & \multirow[b]{2}{*}{ P-value } & \multicolumn{2}{|c|}{ CD133 and CXCR4 } & \multirow[b]{2}{*}{ P-value } \\
\hline & Positive & Negative & & Positive & Negative & & Both positive & Others & \\
\hline Primary cancer & 41 & 23 & & 27 & 37 & & 20 & 44 & \\
\hline Lymph node metastases & 43 & 21 & 0.710 & 15 & 49 & 0.024 & 9 & 55 & 0.020 \\
\hline
\end{tabular}

Table V. Univariate and multivariate analyses of overall survival in the 125 colon cancer patients.

\begin{tabular}{lcccc}
\hline $\begin{array}{l}\text { Clinicopathological } \\
\text { characteristics }\end{array}$ & $\begin{array}{c}\mathrm{n} \\
(\mathrm{n}=125)\end{array}$ & $\begin{array}{c}5 \text {-year survival } \\
\text { rate }\end{array}$ & $\begin{array}{c}\text { Kaplan-Meier } \\
\text { analysis (P-value })\end{array}$ & $\begin{array}{c}\text { Cox regression model } \\
\text { analysis (P-value) }\end{array}$ \\
\hline
\end{tabular}

Age (years)

$<60$

57

Gender

Male

Female

Location

Left hemicolon

Right hemicolon

Pathological grade

G1

G2

G3

Tumor size (cm)

$\begin{array}{ll}<2 & 1 \\ 2-5 & 77 \\ >5 & 34\end{array}$

AJCC stage

II

III

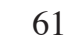

64

Tumor invasion

pT1-T2 ${ }^{\mathrm{a}}$

pT3

pT4

Lymph node status

$\begin{array}{ll}\text { pN0 } & 6 \\ \text { pN1 } & 38 \\ \text { pN2 } & 26\end{array}$

CXCR4 expression

Positive

Negative

CD133 expression

Positive

Negative

CXCR4 and CD133

Both positive

Other combinations
42/57 (73.7\%)

$44 / 68(64.7 \%)$

0.236

0.253

$57 / 78(73.1 \%)$

$29 / 47(61.7 \%)$

0.124

0.162

45/71 (63.4\%)

$41 / 54(75.9 \%)$

0.186

0.154

$10 / 14(71.4 \%)$

$72 / 102(70.6 \%)$

$4 / 9(44.4 \%)$

0.168

0.113

9/14 (64.3\%)

$57 / 77(74.0 \%)$

20/34 (58.8\%)

0.192

0.383

48/61 (78.7\%)

$38 / 64(59.4 \%)$

0.014

0.032

$12 / 16(73.7 \%)$

$44 / 60(73.7 \%)$

$30 / 49(64.7 \%)$

0.237

0.289

48/61 (78.7\%)

25/38 (65.8\%)

$13 / 26(50.0 \%)$

0.011

0.023

$45 / 74(60.8 \%)$

$41 / 51$ (80.4\%)

0.023

0.036

$26 / 45(57.8 \%)$

$60 / 80(75.0 \%)$

0.034

0.021

80

$14 / 29(48.3 \%)$

72/96 (75.0\%)

0.003

0.001

${ }^{\mathrm{a}} \mathrm{As}$ the number of patients with tumors of pT1 and pT2 stages was small, patients from these stages were combined for the analysis. Grading was according to World Health Organization classification; AJCC, American Joint Committee on Cancer. 
A

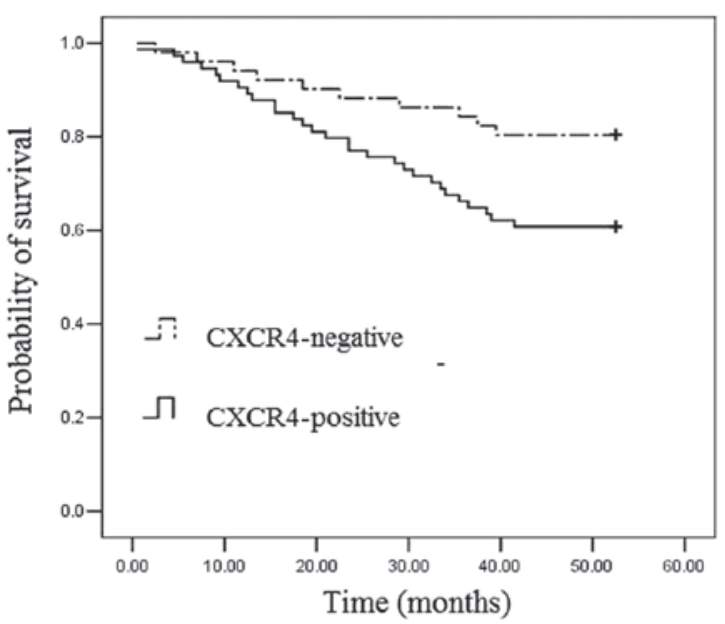

B

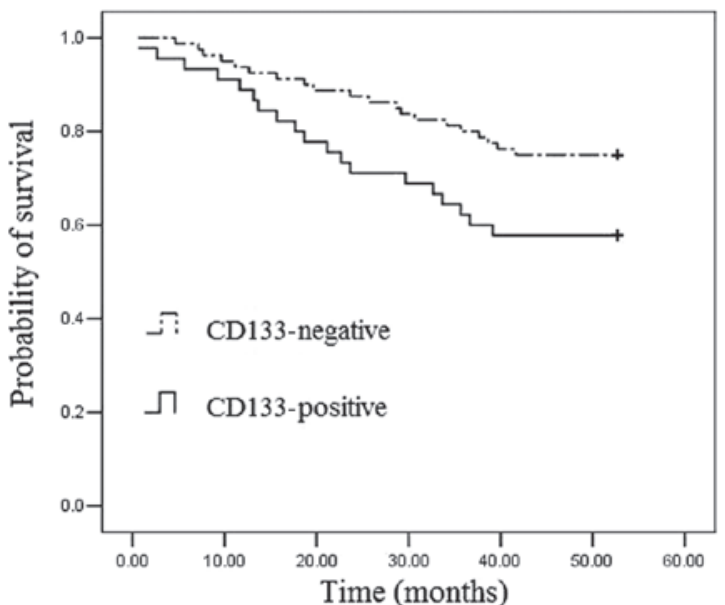

C

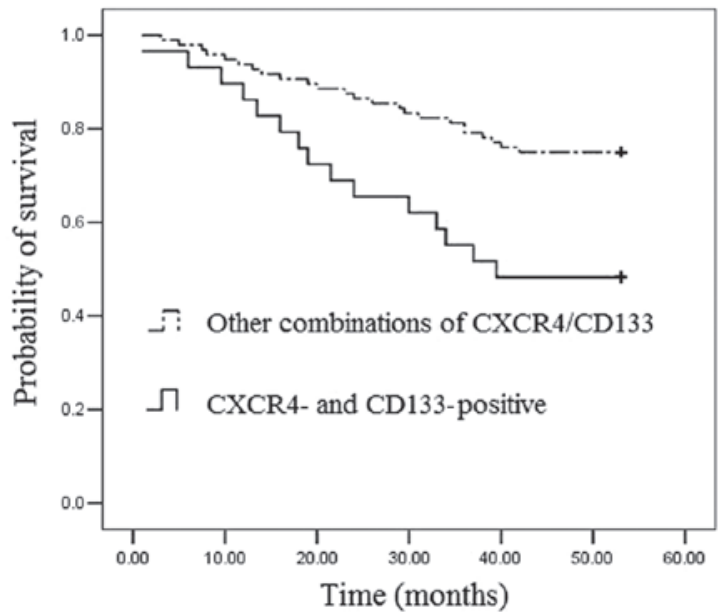

Figure 2. Overall survival cures of colon cancer patients according to (A) CXCR4 expression, (B) CD133 expression and (C) CXCR4/CD133 combinations. Kaplan-Meier survival curves were constructed and pairwise differences were analyzed using the log-rank test.

\section{Discussion}

It has been shown that CXCR4 is critical for the adhesion and/ or migration of tumor cells, indicating that CXCR4 is involved in tumor invasion and metastasis (8). Previous studies have suggested the existence of a cancer stem cell compartment that is able to self-renew and differentiate into mature and diverse cancer cells that are capable of tumor initiation, growth, inva- sion and metastasis (21,22). CD133 is currently one of the best markers for the detection of colon cancer stem cells (28-38). As CXCR4 and CD133 have been implicated in the metastatic process of malignant tumors $(27,41)$, we investigated CXCR4 and CD133 expression in a collection of colon cancer cases that was stratified towards patient outcome.

A number of functional studies investigating the influence of CXCR4 expression and activation by its ligand SDF-1 $\alpha$ (CXCL12) have recently been performed, revealing that CXCR4 is crucial for the adhesion, migration and invasion of tumor cells. The expression of CXCR4 has been shown to be associated with the dissemination of ovarian cancer (42), lymph node metastasis in breast cancer (19) and oral squamous cell carcinoma (20. The results of microarray analyses of cDNA have shown that CXCR4 is also overexpressed in renal (43), esophageal (44) and pancreatic (13) cancer, indicating that CXCR4 expression plays a role in the tumorigenesis of these types of cancer. A previous study used microarray screening of tissues from patients with stage I or II colon cancer to identify CXCR4 as a significant chemokine receptor. Of the 30 patients with tissues showing a high level of expression of CXCR4, two and four experienced local and distant recurrence, respectively. By contrast, during a median follow-up period of 28 months, none of the 27 patients with tissues showing a low level of CXCR4 expression experienced recurrence. CXCR4 expression was found to be a significant prognostic factor for disease-free survival in patients with stage I or II disease and for overall survival in patients with stage IV by multivariate analysis adjusted by clinicopathological characteristics (45). Schimanski et al reported that, although the levels of expression of CXCR4 and CCR7 vary in human colon carcinoma tissues and cell lines, only the expression of CXCR4 has a significant correlation with stage of the disease and lymph node and distant metastasis and an association with a reduced 3-year survival rate (46). Ottaiano et al showed that CXCR4 is expressed in $77.8 \%$ of stage II-III colorectal cancer patients and that CXCR4 expression has a significant prognostic value for disease-free survival using univariate analysis. The authors also reported a significant association between CXCR4 expression and lymph node status (47).

Supporting these data, our clinicopathological study revealed that patients with CXCR4-positive colon cancer had a significantly poorer outcome than those with CXCR4-negative colon cancer, suggesting that CXCR4 is a significant prognostic marker in colon cancer patients. Of the 125 stage II or III colon cancer patients, no significant correlation was observed between CXCR4 expression and gender, age, location of primary mass, pathological grade, tumor size, AJCC stage, tumor invasion or lymph node status (Table II). Ottaiano et al reported that a significant association exists between CXCR4 expression and lymph nodal status (47), but our results demonstrated that no significant correlation existed between CXCR4 expression and lymph node status in stage II or III colon cancer patients. This discrepancy may be due to inadequate patient numbers and the mixed tumor stage.

CD133 is recognized as a marker of cancer and organ-specific stem cells (21-39). A number of previous studies have demonstrated that $\mathrm{CD}_{133^{+}}$, and not CD133- , cells derived from human colon cancer tissues are the only cells that are able to initiate 
tumors in immunodeficient mice. Certain studies isolated cells from colorectal cancer that were capable of initiating tumors and reported that the cells expressed CD133 and exhibited stem cell-like properties $(26,27,48)$. Horst et al reported that the expression of CD133 in colorectal cancer is an independent prognostic marker that was correlated with poor survival in a stratified patient population (49). Kojima et al reported that CD133 expression was detected in only 29 of 189 tumors (15.3\%) and that patients with CD133 overexpression had a significantly poorer overall survival. However, CD133 expression was not found to be an independent risk factor associated with patient survival in multivariate analysis (50). With regard to stage IIIB colon carcinoma patients, Li et al found that a higher percentage of $\mathrm{CD}_{133}{ }^{+}$cells was associated with poor prognosis in patients with stage IIIB tumors (51). These contradicting results seem not to provide enough evidence of the malignant potential of CD133-positive cells. As cancer stem cells divide slowly, they are considered to be resistant to most of the current chemotherapies that target differentiated or highly proliferating tumor cells. Ong et al provided evidence that the expression of CD133 is associated with the poor response of colorectal cancer to 5-Fu-based chemotherapy, as well as with poor prognosis (52).

Our results showed that CD133 expression was detected in 45 of the 125 tumors $(36.0 \%)$ and that CD133+ cancer cells contributed to the progression of stage II and III colon cancer, suggesting that CD133 is a significant prognostic marker in colon cancer patients. Moreover, we found the CD133 antigen at the luminal surface of epithelial tumor glands with shedding into the lumina. This result is in agreement with those of previous studies in which CD133 was detected in embryonal tissue and on the apical surface of the cultured colon cancer cell line Caco-2 (53). Among the 125 stage II or III colon cancer patients, no significant correlation was found between CD133 expression and gender, age, location of primary mass, pathological grade, tumor size, AJCC stage, tumor invasion or lymph node status (Table II). These contradicting results seem not to provide enough evidence of the malignant potential of CD133 positive cells. A larger study with a greater number of CD133-positive cases may show a more marked association between CD133 expression and clinicopathological features. Although the function of CD133 has not yet been elucidated, the chemoresistance of CD133-positive cells may result in the poor survival rate of patients with CD133-positive tumors (54).

One possibility is that the number of CD133-positive cells is increased during cancer progression, rather than having a biological function associated with the malignancy of colon cancer. In addition, we found that the tumor cells positive for CD133 also tended to be positive for CXCR4. In the present study, we showed that neither CXCR4 nor CD133 expression was able to predict lymph node metastases in stage II-III colon cancer, but the combination of the expression of CXCR4 and CD133 was able to predict lymph node metastasis in stage II-III colon cancer; these data confirm that CXCR4- and CD133-positive cells are more prone to metastasize to the draining lymph nodes. Although only 29 (23.2\%) CXCR4- and CD133-positive cases were identified in our series and further investigation in a larger series of CXCR4- and CD133-positive cases may be necessary, cases which were positive for both CXCR4 and CD133 expression had a poorer outcome than the other combinations of CXCR4 and CD133 expression.
In addition, CXCR4 and CD133 expression was observed more frequently in advanced cancers. The chemoresistance of CXCR4- and CD133-positive cells may also be associated with the poor survival of patients whose tumors are positive for CXCR4 and CD133.

Furthermore, we analyzed the expression of CXCR4 and CD133 in the related lymph nodes. The results suggested that, compared with their primary lesions, the co-expression of the CXCR4 and CD133 proteins was significantly decreased in the MTLNs. Specifically, there was no difference in the expression of CXCR4 in the primary lesions and MTLNs, but the expression of CD133 was downregulated in the subset of tumor cells following the lymph node metastatic transition. Colon cancer may also encompass heterogeneous subtypes that include CD133-positive cells with stem cell-like properties and CD133-negative cells and several studies have suggested that CD133 expression is not limited to organ-specific stem cells (55-57). One explanation for this phenomenon is that all the cancerous cells in primary colon tumors are $\mathrm{CD}_{133^{+}}$, so the cancer stem cells are included in this population. CD133 cells may then appear at the epithelial-mesenchymal transition and result in metastasis (58). Shmelkov et al proposed that the expression of CD133 is not limited to tumor-initiating or intestinal stem cells and that, during metastasis, CD133 ${ }^{+}$ tumor cells generate CD133- cells, which are more aggressive and also able to initiate tumors in nude mice. The authors reported that $40 \%$ of metastatic tumors in their study were CD133-negative, indicating that $\mathrm{CD}_{133}{ }^{+}$cells are not the cause of the tumors (58).

Our results showed that, compared with the expression of CD133 in the primary lesions, CD133 expression was significantly decreased in the MTLNs. This result is consistent with those of previous studies concerning CD133 expression in metastatic tumors.

In conclusion, we demonstrated that the co-expression of the CXCR4 and CD133 proteins is closely associated with lymph node metastasis and poor prognosis in patients with colon cancer. We also provide further evidence that the co-expression of the CXCR4 and CD133 proteins in the tumor cell population of colon cancer is specifically, although not exclusively, significant in colon cancer progression. Furthermore, the concomitant positive expression of CXCR4 and CD133 is an independent predictor of survival in stage II-III colon cancer patients. Confirmation of this observation in independent colon cancer cohorts could lead to the improved targeting of conventional cytotoxic therapies to the patient subgroups that are most likely to benefit.

\section{Acknowledgements}

This study was supported by the Guangdong Natural Science Foundation (grant no. 10251051501000008).

\section{References}

1. Weir HK, Thun MJ, Hankey BF, et al: Annual report to the nation on the status of cancer, 1975-2000, featuring the uses of surveillance data for cancer prevention and control. J Natl Cancer Inst 95: 1276-1299, 2003.

2. Singh R, Lillard JW Jr and Singh S: Chemokines: key players in cancer progression and metastasis. Front Biosci (Schol Ed) 3: $1569-1582,2011$ 
3. Liekens S, Schols D and Hatse S: CXCL12-CXCR4 axis in angiogenesis, metastasis and stem cell mobilization. Curr Pharm Des 16: 3903-3920, 2010.

4. Arya M, Patel HR and Williamson M: Chemokines: key players in cancer. Curr Med Res Opin 19: 557-564, 2003.

5. Ali S and Lazennec G: Chemokines: novel targets for breast cancer metastasis. Cancer Metastasis Rev 26: 401-420, 2007.

6. Murdoch C: CXCR4: chemokine receptor extraordinaire. Immunol Rev 177: 175-184, 2000.

7. Phillips RJ, Burdick MD, Lutz M, Belperio JA, Keane MP and Strieter RM: The stromal derived factor-1/CXCL12-CXC chemokine receptor 4 biological axis in non-small cell lung cancer metastases. Am J Respir Crit Care Med 167: 1676-1686, 2003.

8. Kawamata H, Furihata T, Omotehara F, et al: Identification of genes differentially expressed in a newly isolated human metastasizing esophageal cancer cell line, T.Tn-AT1, by cDNA microarray. Cancer Sci 94: 699-706, 2003.

9. Bachelder RE, Wendt MA and Mercurio AM: Vascular endothelial growth factor promotes breast carcinoma invasion in an autocrine manner by regulating the chemokine receptor CXCR4 Cancer Res 62: 7203-7206, 2002.

10. Kijima T, Maulik G, Ma PC, et al: Regulation of cellular proliferation, cytoskeletal function, and signal transduction through CXCR4 and c-Kit in small cell lung cancer cells. Cancer Res 62 6304-6311, 2002.

11. Gao Z, Wang X, Wu K, Zhao Y and Hu G: Pancreatic stellate cells increase the invasion of human pancreatic cancer cells through the stromal cell-derived factor-1/CXCR4 axis. Pancreatology 10 $186-193,2010$

12. Guleng B, Tateishi K, Ohta M, et al: Blockade of the stromal cellderived factor-1/CXCR4 axis attenuates in vivo tumor growth by inhibiting angiogenesis in a vascular endothelial growth factorindependent manner. Cancer Res 65: 5864-5871, 2005.

13. Koshiba T, Hosotani R, Miyamoto Y, et al: Expression of stromal cell-derived factor 1 and CXCR4 ligand receptor system in pancreatic cancer: a possible role for tumor progression. Clin Cancer Res 6: 3530-3535, 2000.

14. Van der Meulen AA, Biber K, Lukovac S, et al: The role of CXC chemokine ligand (CXCL)12-CXC chemokine receptor (CXCR)4 signalling in the migration of neural stem cells towards a brain tumour. Neuropathol Appl Neurobiol 35: 579-591, 2009.

15. Li W, Gomez E and Zhang Z: Immunohistochemical expression of stromal cell-derived factor-1 (SDF-1) and CXCR4 ligand receptor system in hepatocellular carcinoma. J Exp Clin Cancer Res 26: 527-533, 2007.

16. Chen GS, Yu HS, Lan CC, et al: CXC chemokine receptor CXCR4 expression enhances tumorigenesis and angiogenesis of basal cell carcinoma. Br J Dermatol 154: 910-918, 2006.

17. Barbero S, Bonavia R, Bajetto A, et al: Stromal cell-derived factor lalpha stimulates human glioblastoma cell growth through the activation of both extracellular signal-regulated kinases $1 / 2$ and Akt. Cancer Res 63: 1969-1974, 2003.

18. Zeelenberg IS, Ruuls-Van Stalle L and Roos E: The chemokine receptor CXCR4 is required for outgrowth of colon carcinoma micrometastases. Cancer Res 63: 3833-3839, 2003.

19. Kato M, Kitayama J, Kazama S and Nagawa H: Expression pattern of CXC chemokine receptor-4 is correlated with lymph node metastasis in human invasive ductal carcinoma. Breast Cancer Res 5: 144-150, 2003.

20. Uchida D, Begum NM, Almofti A, et al: Possible role of stromalcell-derived factor-1/CXCR4 signaling on lymph node metastasis of oral squamous cell carcinoma. Exp Cell Res 290: 289-302, 2003.

21. Singh A and Settleman J: EMT, cancer stem cells and drug resistance: an emerging axis of evil in the war on cancer. Oncogene 29: 4741-4751, 2010.

22. Todaro M, Francipane MG, Medema JP and Stassi G: Colon cancer stem cells: promise of targeted therapy. Gastroenterology 138: 2151-2162, 2010

23. Boman BM and Wicha MS: Cancer stem cells: a step toward the cure. J Clin Oncol 26: 2795-2799, 2008

24. Wang J, Guo LP, Chen LZ, Zeng YX and Lu SH: Identification of cancer stem cell-like side population cells in human nasopharyngeal carcinoma cell line. Cancer Res 67: 3716-3724, 2007.

25. Horst D, Kriegl L, Engel J, Kirchner T and Jung A: Prognostic significance of the cancer stem cell markers CD133, CD44, and CD166 in colorectal cancer. Cancer Invest 27: 844-850, 2009.

26. O'Brien CA, Pollett A, Gallinger S and Dick JE: A human colon cancer cell capable of initiating tumour growth in immunodeficient mice. Nature 445: 106-110, 2007.
27. Ricci-Vitiani L, Lombardi DG, Pilozzi E, et al: Identification and expansion of human colon-cancer-initiating cells. Nature 445 : 111-115, 2007.

28. Murat A, Migliavacca E, Gorlia T, et al: Stem cell-related 'selfrenewal' signature and high epidermal growth factor receptor expression associated with resistance to concomitant chemoradiotherapy in glioblastoma. J Clin Oncol 26: 3015-3024, 2008.

29. Hambardzumyan D, Squatrito M and Holland EC: Radiation resistance and stem-like cells in brain tumors. Cancer Cell 10: 454-456, 2006.

30. Clement V, Sanchez P, de Tribolet N, Radovanovic I and Ruiz i Altaba A: HEDGEHOG-GLI1 signaling regulates human glioma growth, cancer stem cell self-renewal, and tumorigenicity. Curr Biol 17: 165-172, 2007.

31. Hambardzumyan D, Becher OJ and Holland EC: Cancer stem cells and survival pathways. Cell Cycle 7: 1371-1378, 2008

32. Bao S, Wu Q, McLendon RE, et al: Glioma stem cells promote radioresistance by preferential activation of the DNA damage response. Nature 444: 756-760, 2006.

33. Griguer CE, Oliva CR, Gobin E, et al: CD133 is a marker of bioenergetic stress in human glioma. PLoS One 3: e3655, 2008.

34. Eramo A, Lotti F, Sette G, et al: Identification and expansion of the tumorigenic lung cancer stem cell population. Cell Death Differ 15: 504-514, 2008.

35. Ma S, Chan KW, Hu L, et al: Identification and characterization of tumorigenic liver cancer stem/progenitor cells. Gastroenterology 132: 2542-2556, 2007.

36. Yin AH, Miraglia S, Zanjani ED, et al: AC133, a novel marker for human hematopoietic stem and progenitor cells. Blood 90: 5002-5012, 1997.

37. Monzani E, Facchetti F, Galmozzi E, et al: Melanoma contains CD133 and ABCG2 positive cells with enhanced tumourigenic potential. Eur J Cancer 43: 935-946, 2007.

38. Wright MH, Calcagno AM, Salcido CD, Carlson MD, Ambudkar SV and Varticovski L: Brcal breast tumors contain distinct $\mathrm{CD} 44^{+} / \mathrm{CD} 24^{-}$and $\mathrm{CD} 133^{+}$cells with cancer stem cell characteristics. Breast Cancer Res 10: R10, 2008.

39. Boman BM and Huang E: Human colon cancer stem cells: a new paradigm in gastrointestinal oncology. J Clin Oncol 26: 2828-2838, 2008

40. Matsumoto K, Shariat SF, Ayala GE, Rauen KA and Lerner SP: Loss of coxsackie and adenovirus receptor expression is associated with features of aggressive bladder cancer. Urology 66 : 441-446, 2005.

41. Brabletz T, Jung A, Spaderna S, Hlubek F and Kirchner T: Opinion: migrating cancer stem cells - an integrated concept of malignant tumour progression. Nat Rev Cancer 5: 744-749, 2005.

42. Kajiyama H, Shibata K, Terauchi M, Ino K, Nawa A and Kikkawa F: Involvement of SDF-1alpha/CXCR4 axis in the enhanced peritoneal metastasis of epithelial ovarian carcinoma. Int J Cancer 122: 91-99, 2008.

43. Schrader AJ, Lechner O, Templin M, et al: CXCR4/CXCL12 expression and signalling in kidney cancer. Br J Cancer 86: 1250-1256, 2002.

44. Sasaki K, Natsugoe S, Ishigami S, et al: Expression of CXCL12 and its receptor CXCR4 correlates with lymph node metastasis in submucosal esophageal cancer. J Surg Oncol 97: 433-438, 2008.

45. Kim J, Takeuchi H, Lam ST, et al: Chemokine receptor CXCR4 expression in colorectal cancer patients increases the risk for recurrence and for poor survival. J Clin Oncol 23: 2744-2753, 2005.

46. Schimanski CC, Schwald S, Simiantonaki N, et al: Effect of chemokine receptors CXCR4 and CCR7 on the metastatic behavior of human colorectal cancer. Clin Cancer Res 11: $1743-1750,2005$

47. Ottaiano A, Franco R, Aiello Talamanca A, et al: Overexpression of both CXC chemokine receptor 4 and vascular endothelial growth factor proteins predicts early distant relapse in stage II-III colorectal cancer patients. Clin Cancer Res 12: 2795-2803, 2006.

48. Todaro M, Alea MP, Di Stefano AB, et al: Colon cancer stem cells dictate tumor growth and resist cell death by production of interleukin-4. Cell Stem Cell 1: 389-402, 2007.

49. Horst D, Kriegl L, Engel J, Kirchner T and Jung A: CD133 expression is an independent prognostic marker for low survival in colorectal cancer. Br J Cancer 99: 1285-1289, 2008.

50. Kojima M, Ishii G, Atsumi N, Fujii S, Saito N and Ochiai A: Immunohistochemical detection of CD133 expression in colorectal cancer: a clinicopathological study. Cancer Sci 99: 1578-1583, 2008. 
51. Li CY, Li BX, Liang Y, et al: Higher percentage of CD133+ cells is associated with poor prognosis in colon carcinoma patients with stage IIIB. J Transl Med 7: 56, 2009.

52. Ong CW, Kim LG, Kong HH, et al: CD133 expression predicts for non-response to chemotherapy in colorectal cancer. Mod Pathol 23: 450-457, 2010.

53. Corbeil D, Röper K, Hellwig A, et al: The human AC133 hematopoietic stem cell antigen is also expressed in epithelial cells and targeted to plasma membrane protrusions. J Biol Chem 275: 5512-5520, 2000

54. Liu G, Yuan X, Zeng Z, et al: Analysis of gene expression and chemoresistance of CD133+ cancer stem cells in glioblastoma. Mol Cancer 5: 67, 2006.

55. Florek M, Haase M, Marzesco AM, et al: Prominin-1/CD133, a neural and hematopoietic stem cell marker, is expressed in adult human differentiated cells and certain types of kidney cancer. Cell Tissue Res 319: 15-26, 2005.
56. Pfenninger CV, Roschupkina T, Hertwig F, et al: CD133 is not present on neurogenic astrocytes in the adult subventricular zone, but on embryonic neural stem cells, ependymal cells, and glioblastoma cells. Cancer Res 67: 5727-5736, 2007.

57. Weigmann A, Corbeil D, Hellwig A and Huttner WB: Prominin, a novel microvilli-specific polytopic membrane protein of the apical surface of epithelial cells, is targeted to plasmalemmal protrusions of non-epithelial cells. Proc Natl Acad Sci USA 94: 12425-12430, 1997.

58. Shmelkov SV, Butler JM, Hooper AT, et al: CD133 expression is not restricted to stem cells, and both $\mathrm{CD} 133^{+}$and CD133 metastatic colon cancer cells initiate tumors. J Clin Invest 118: 2111-2120, 2008 